\title{
"Evaluating Painters All Over the Country" Guo Xi and His Landscape Painting
}

\author{
$\operatorname{Min} \mathrm{Ma}^{1, *}$ \\ ${ }^{1}$ Academy of Arts \& Design, Tsinghua University, Beijing, China \\ *Corresponding author. Email: 52200343@qq.com
}

\begin{abstract}
Styled Chunfu, Guo Xi was a native of Wenxian County. In the beginning, he learned from the methods of $\mathrm{Li}$ Cheng, yet he was rather good at expressing his own feelings, thus becoming adept at surpassing his master and creating a main school of the royal court landscape painting in the Northern Song Dynasty whose influence had lasted to later ages. Linquan Gaozhi Ji, Guo Xi's well-known theory on landscape painting, was a book emerged after the art of landscape painting in the became highly mature in the Northern Song Dynasty, which was an unprecedented peak in landscape painting and a rich treasure house in the history of landscape painting.
\end{abstract}

\section{Keywords: Guo Xi, Linquan Gaozhi, landscape painting}

\section{INTRODUCTION}

Great progress had been made in the creation of panoramic landscape paintings in China during the Northern Song Dynasty, after the innovations of Jing Hao, Guan Tong, Dong Yuan and Ju Ran, when a number of influential landscape painters and exquisite landscape paintings emerged. Guo $\mathrm{Xi}$ had a high reputation in painting, and the landscape painting in the painting academy of the Northern Song Dynasty took a completely new look after Guo Xi entered it. Guo Xi's painting style gradually became the mainstream in the painting academy at that time. On the one hand, it was because Emperor Shenzong highly appreciated his paintings; on the other hand, it was because of Guo Xi's brilliant talents and ability. Later, the royal family entrusted him with the duty of "evaluating painters all over China", which further boosted his influence and social status. For that reason, his painting style was followed by a large number of painters at that time. At the same time, the landscape painting of Guo $\mathrm{Xi}$ was the transition stage of "realistic" painting in the history of royal court painting, which had served as a link between the past and the coming period. It supported the "realistic" spirit from Emperor Huizong and the painting academy in the Northern Song Dynasty to the royal court painting with mature techniques, thus becoming an extremely important historical stage in the evolution of the Chinese painting.

Secondly, in Guo Xi's life, he summarized the artistic practice of his predecessors and himself and wrote down important painting theories. Therefore, he had also made a great contribution in painting theories.
Linquan Gaozhi Ji wrote by Guo $\mathrm{Xi}$ and his son Guo $\mathrm{Si}$ in 1080 was a classic book on landscape painting as the art of landscape painting became highly mature in the Northern Song Dynasty. The book was written in the late Northern Song Dynasty, when the art of landscape painting in China had already entered a relatively mature stage. At that time, artists had accumulated a lot of experience. "Especially Guo Xi, as a brilliant painter, had reached a rather high level in landscape painting. At that time, he was praised as 'unique in this age". ${ }^{1}$ It's this combination of his own practice of creation and the artistic experience of his predecessors that had allowed Linquan Gaozhi Ji to have its own characteristics. His painting theories did not fall into the set pattern of his predecessors. In his painting theories, he did not focus on the appreciation, comment and literature record of the landscape painting works of predecessors, like in many painting theories before, nor did he express his personal impression of viewing paintings or the painting theories of his predecessors. Instead, it's a book written on the basis of his meticulous experience of philosophy and art, attitude towards life, methods of creation, painting techniques and expression of artistic conception. Therefore, the book was more personal with more profound, specific and operable views. His classic theories of landscape painting, such as "painters must have the heart of forests and springs", "they should be all-embracing instead of being limited to their own theories" and "the combination of looking far and looking close in observation" have had far-reaching

Wang Huangsheng, Hu Guanghua. Special History of Chinese Painting: Landscape Painting [M]. Jiangxi Fine Arts Publishing House. 2008(12):219. 
influence and extraordinary significance in the landscape painting creation both in the Northern Song Dynasty and in the contemporary age.

By analyzing the characteristics of Guo Xi's landscape painting, it can be seen that Guo Xi was very meticulous in painting, and that he often thought about theoretical issues of landscape painting. In the appreciation of landscape paintings, the songs of apes and birds could vaguely be heard, and the views of the mountains and waters were lifelike. In this way, landscape paintings became the substitution of real landscape, which could arouse the viewers' aesthetic association and aesthetic enjoyment. In addition, landscape paintings could make people feel that they could walk, view, travel and dwell in the paintings.

\section{GUO XI'S LIFE AND HIS ARTISTIC \\ CREATION}

\section{A. The time of birth and death of Guo Xi}

In terms of the time of birth and death of Guo $\mathrm{Xi}$, modern literati, historians, art historians and connoisseurs have made great achievements with their tireless efforts and rich academic experience and through careful studies. However, in the issue of the time of birth and death of Guo Xi, there are different opinions. The following possibilities have been put forward: the first theory is that Guo Xi lived between 1000 and 1090, which was put forward by $\mathrm{Mr}$. Xu Fuguan in The Spirit of Chinese Art published by Guangxi Normal University Press, and echoed by Mr. Chen Chuanxi in The History of Chinese Landscape Painting; the second theory is that Guo $\mathrm{Xi}$ lived between 1000 and 1087, which was put forward by Wang Chaowen in The History of Chinese Art; the third theory is that "Guo Xi lived between 1023 and 1085, which was mentioned by Mr. Wang Bomin in The Comprehensive History of Chinese Painting published by SDX Joint Publishing Company, which he said was put forward by Pang Yuanji and he also agreed on." 2

According to records about what Yuan Haowen said, Guo $\mathrm{Xi}$ was already 80 in the first year of Yuanyou, meaning that he was 89 in the ninth year of Yuanyou, namely the first year of Shaosheng (1094). According to relevant literature, Yuan Haowen described Guo Xi in Two Poems about Guo Xi's Xishan Wanqiu as "a celestial man having his fun in his 90s", which is consistent with the deduction of the author. According to the above sentence written by Yuan Haowen, Guo Xi should be exactly 90. However, we should not understand it literally. Su Shi, his brother and their disciples referred to Guo $\mathrm{Xi}$ in their poems as Grey-head and Elder, and the fact that Yuan Haowen

\footnotetext{
Wang Bomin. Comprehensive History of Chinese Painting [M]. Beijing: SDX Joint Publishing Company. 2018(11):374.
}

mentioned twice in his poems that Guo $\mathrm{Xi}$ was more than 80 years old, it is quite understandable that they might refer to him as a "celestial man" close to 90 . Therefore, combining the records in literature, convincing information in poems and the calculation and analysis of the author, we can conclude that Guo Xi died in the last year of Yuanyou (1094), when Guo Xi was 89 year old, which is consistent with the historical record that Guo Xi was one of the few painters in the Northern Song Dynasty who live a long life. Thus, the year of Guo Xi's birth was then around 1005. which was basically consistent with the records in all kinds of literature and art history that Guo Xi lived a long life, "which was also basically consistent with scholars' deduction that Guo Xi was born in around 1000-1010 and died in around 1090."3

\section{B. Guo Xi's art creation}

1) Early stages of Guo Xi's art creation: When he was still young, Guo Xi already had a reputation in painting. According to the records in the Prologue of Linquan Gaozhi Ji, Guo Xi learned Taoism when he was young, which enabled him to renew himself and drove him to travel around. None of his ancestors was engaged in painting, and it was his natural gift. Thus he explored in art and became famous in this field". The scroll of Landscape was painted by Guo $\mathrm{Xi}$ when he was young. When observed carefully, this painting was different from his works during the Xining period in terms of techniques, yet from his expression of mountains, trees and river mouths, it can be seen that it was painted in the Northern Song Dynasty. The existing Scroll of Landscape is with a postscript by Ren Xun from the Jin Dynasty,saying that Guo Xi painted this painting when he was young. This is his earliest painting according to historical records. In 1054, there was another record that Guo Xi copied Li Cheng's Painting of the Sudden Rain, which is seen in the Postscript of Guo Xi's Bowled Landscape by Huang Shangu. From Landscape and Painting of the Sudden Rain that Guo Xi painted in his early years, we can see that Guo Xi had made great progress in his techniques.

2) The peak of Guo Xi's art creation: In 1068, the first year of Xining, Guo Xi enter the capital city with superb skills of painting. Once he got to the capital, Guo Xi began a series of intensive creation. First, he painted on a wall for Wu Zhongfu, the Chancellor of Treasury; later, he painted six screens of wind, rain, water and stones for Shao Kang, the Governor of the Kaifeng Prefecture; he painted screens of snow storms for Wu Zhengxian, Deputy Chancellor of Salt and Iron,

Xu Gufuan. The Spirits of Chinese Art [M]. Guangx Normal University Press. Edition 1. 2007(1), printed for the second time in 2008(2):254. 
six screens of pines and stones for a Yan, an old friend of Zhang Jianfu, a judge in Dushui as well as six screens of wind, rain, water and stones for the House of Suggestions. In addition to the offices of various officials, "Guo Xi's paintings were also used to decorate royal buildings. He painted the Painting of the Brook Valley for Xiangguo Temple, and painted the screens of the Zichen Hall together with Ai Xuan, Cui Bai and Ge Shouchang;"4 and he painted the screens of the Small Hall together with Li Zongcheng adn Fu Daoyin (he painted the central screens while $\mathrm{Li}$ and Fu painted the ones on both sides). These frequent artistic activities must had deepened Emperor Shenzong's impression of Guo $\mathrm{Xi}$, and the Emperor ordered Guo $\mathrm{Xi}$ to the Imperial Academy and paint the screens in front of the emperor. After Guo Xi painted on countless screens of different sizes, Emperor Shenzong checked them and was greatly pleased. Naturally, Guo Xi was rewarded by Emperor Shenzong, who conferred him the title of Artist of the Imperial Academy, marking the beginning of the peak of his career. May he was tired of the frequent social activities, or perhaps he was trying to show an attitude, Guo $\mathrm{Xi}$ "begged to return with the excuse of serving the parents", which was rejected by the emperor. Then he "begged to hear the orders of the Emperor", requiring to directly follow the orders of the emperor himself, so as to avoid a lot of unnecessary things, which was approved by the emperor. Since then, Guo $\mathrm{Xi}$ became the favorite painter among many imperial painters, the screens he painted were used in such places in the palace as the Huacheng Hall, Qinming Hall, Ruisi Hall, Yaojin Pavilion and Da'annian, all the screen walls of various halls in the Department of State Affairs, the Central Secretariat and the Scholars' Academy were his works. Among these works, the Landscape of Spring Mountains looked tranquil and pleasing, which was praised by Su Dongpo with a poem: "The spring day in a jade hall was such a leisure, with painting of spring mountains by Guo Xi. The young swallows look like they have just waken, and the white waters and green mountains look as if they are not earthly landscapes". Emperor Shenzong loved Guo Xi's paintings and didn't treat him as an ordinary craftsman. Besides being used to decorate the imperial palace, Guo Xi's paintings were all used as royal gifts, "the Painting of Spring Snow in the Mountains was given to Qiwang, and Autumn Views and Mists were given to Korea as state gifts." ${ }^{5}$ Emperor

Xu Jianrong. Appreciation of Famous Paintings in the Song Dynasty. Shanghai Bookstore Publishing House. 1999:p.168, p.220.

Guo Si. Records of Painting, in which it was recorded that Guo $\mathrm{Xi}$ was ordered by the emperor to finish two paintings, respectively about autumn rain and winter snow, which were given to
Shenzong ascended the throne in the first year of Xining (1068) and died in the eighth year of Yuanfeng (1085), which was also the peak of art creation in Gao Xi's career. The years of painting were marked on the Painting of Early Spring, the Painting of Spring Snow in the Mountains and the Painting of Nest and Stones, the existing paintings of Guo $\mathrm{Xi}$, showing that the first two paintings were painted in the fifth year of Xining (1072), and the third was painted in the first year of Yuanfeng (1078), all painted in the peak period of his art career.

3) The end of Gao Xi's art creation: In his nearly twenty years of practice during the reign of Emperor Shenzong, Guo Xi's painting style was popular among the imperial court and the commonalty. However, Emperor Zhezong who ascend the throne later was not very interested in his paintings, and ordered to put all his paintings in the palace back to the storage, and replace them with ancient paintings. Throughout the history of landscape painting in China, it's easy to see that although Guo $\mathrm{Xi}$ received totally different treatments in the imperial court, he did not disappear after he lost the support of the emperor, as many imperial painters did. On the contrary, he continued to have a very high reputation in the society. In his late years, Guo Xi was greatly praised by a lot of literati: Huang Tingjian said that "Guo $\mathrm{Xi}$ is the only painter who can still paint landscapes as a Grey-head" and "Guo Xi can still express the feeling of landscapes, and his sight remains sharp although he is already an old man"; Su Zhe wrote the following sentence in his poem "all said that ancient people are no longer seen, yet they haven't seen the white-headed man waiting for imperial order in the north gate". The appraisals of the scholarofficials became more and more influential, and the choice of the court could no longer affect people attitude towards his works.

\section{A STUDY ON GUO XI'S LANDSCAPE PAINTING CREATION FROM THE PERSPECTIVE OF LINQUAN GAOZHI}

According to the Abstract of the Contents of Complete Library in the Four Branches of Literature, the first four essays in Linquan Gaozhi, namely Words about Landscapes, Spirit of Painting, Secrets of Painting and Discussions about Painting were written by Guo $\mathrm{Xi}$ and compiled by Guo $\mathrm{Si}$, his son; while the prologue and the last two essays, namely

Qiwang... another two paintings about mists, which were given to Korean... the inscription on the Painting of Snow in Spring Mountains was: Painting of snow in spring mountains painted according to the order of the emperor. Therefore, this painting was probably painted for Qiwang. 
Complementary Discussion about the Rules of Painting and Record of Painting were written by Guo Si, followed by the postscript by $\mathrm{Xu}$ Guangning. This book is a very important reference for us to know the creation and thoughts of Guo $\mathrm{Xi}$.

First, Guo Xi insisted that painters must have the heart of forests and springs.

In Guo Xi's opinion, whoever paint landscape painting must go deep into the nature to observe and experience it deeply, that they should visit attractions of different places so that they could have landscapes in this mind, thus achieving the state of "painting smoothly out of rich storage of landscapes in the mind". Guo $\mathrm{Xi}$ attached particular importance to the observation of natural landscapes, requiring that painters must have "the heart of forests and springs" so that they could gain. In his opinion, in painters' observation of landscapes, two issues were involved: the issue of method and the issue of attitude. He once said: "There are rules in observing landscapes: the value is high if painters copy with the heart of forests and springs, while the value is low if they copy from the perspective of pride." 6 , which fully demonstrated the necessity of mastery through comprehensive studies, experiencing through the heart and remaining sincere and modest, and it also demonstrated his attitude of abandoning utility, treating things with a tranquil heart, cultivation of morality and staying natural.

Secondly, Guo Xi held that painters should be allembracing instead of being limited to their own theories.

In Linquan Gaozhi, Guo Xi clearly put forward that painters should be "all-embracing" instead of being limited to their own theories, which was coherent to his theories of "breadth of mind" and "state". In Words about Landscapes in Linquan Gaozhi Ji, Guo Xi comprehensively expressed his thoughts and experience in the creation of landscape paintings. He held that when studying from tradition, one should not be "limited to one theory", but should absorb theories from different aspects, thus "developing our own theories", which reflected what he gained from his own experience.

Guo $\mathrm{Xi}$ emphasized the method of combining looking far and looking close in observation.

In terms of landscape painting creation, Guo $\mathrm{Xi}$ developed the theory of "being brilliant in manners and quality" put forward by Jing Hao from the Five Dynasties in his Records of Brush Techniques. Guo Xi expressed that "in painting of realistic mountains and

Guo Xi. Linquan Gaozhi, Compilation of Ancient Painting Theories in China (1) [M]. Beijing: People's Fine Arts Publishing House, 2000:640-632. waters, painters should look far to get the manners, and look close to get the quality." In other words, to realize the state of "brilliance in manners and quality", painters needed to combine the method of looking far and the method of looking close.

When summarizing the methods of observing mountains, Guo Xi said that "people must observe the mountains from a distance, so that they can get the overall manners of them." from the perspective of a landscape painter, Guo Xi summarized the different effects people could gain by "looking far", and came up with the theory of "three distant effects of mountains" which had a far-reaching influence:

"Three effects can be gained by observing mountains from a distance: the effect gained through looking up is called vertical distance; the effect gained through looking from the mountains in the front to those behind is called deep distance; the effect gained through looking from mountains close to distant mountains is called horizontal distance. The colors of vertical distance are clear, the colors of deep distance are vague, and the colors of horizontal distance are a combination of clarity and vagueness. In vertical distance, the mountains tower, in deep distance, the mountains are in layers, and in horizontal distance, the mountains are mixed and dimly discernible. When people are placed in these three distances, they look bright in the vertical distance, small in the deep distance and vague in the horizontal distance. The bright ones are not short, the small ones are not long and the vague ones are not big. This is called the 'three distances'".

Not only did the theory of "three distances" make higher requirements for the creation of landscape painting, it's also combined with the theory of multipoint perspective in Chinese painting put forward before, thus pushing the aesthetic boundaries of landscape painting.

\section{THE REFLECTION OF THE CHARACTERISTICS OF GUO XI IN HIS LANDSCAPE PAINTINGS}

Completely preserved works of Guo Xi include Early Spring in Museum of Taiwan, Painting of Serene Valley and Painting of Mountain Villages in Shanghai Museum and Painting of Nest and Stones in the Palace Museum.

\footnotetext{
Guo Xi, Guo Si (Song Dynasty): Linquan Gaozhi: Words about Landscape Painting.
} 


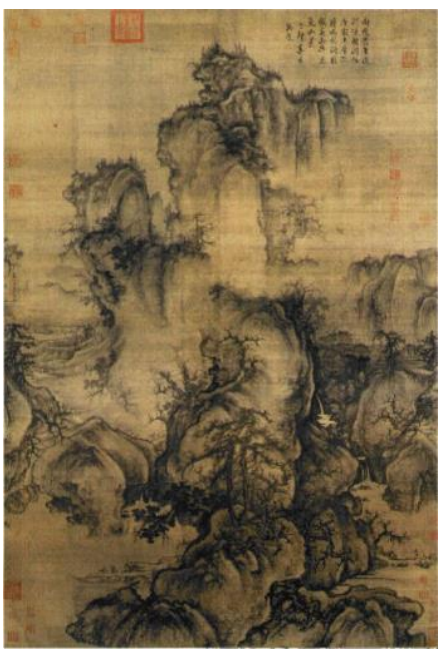

Fig. 1. Early Spring — Guo Xi (Northern Song Dynasty).

Take a look at Early Spring ("Fig. 1"). This is a large vertical-scroll painting. In the Northern Song Dynasty, the technology was not advanced enough to produce silk pieces that large, so this painting was painted on two pieces of silk bonded together. In this painting, Guo $\mathrm{Xi}$ elaborately arranged layers of mountains, brooks, decorated with aged and young trees, people and houses. The mountains were surrounded by flowing mists in the waist, which looks clear and vague, full of changes. It's obvious that Guo $\mathrm{Xi}$ was willing to show his outstanding painting techniques and skills of organization. As we can see, each stone and each tree in this painting looked realistic, with vivid details. Not only dis Early Spring adopt a complicated structure, it's also with a lot of layers. In the field of large landscape paintings, the pattern of Fan Kuan was the example, which emphasized "being thick in all four sides". Different from that, Early Spring set a new fashion of elegance and flexibility. There were pedestrians, fishermen, towers, pavilions and bridges, yet they didn't make people feel the tiredness of travels, but rather made people have the feeling that they could walk, view, dwell and travel inside, thus making people forget earthly concerns and reaching the state of cleanness with a heart of forests and springs. This feeling constructed in the painting was what Guo Xi pursued hard. Through carefully appreciating Early Spring, we can see that not only was the composition of mountains, stones, water, people, boats and houses unique, the specific locations of the towers and pavilions were also well-conceived. A towering mountain stands in the front, surrounded by serene waterfalls, and the suddenly entering fishing boat naturally creates a feeling of movement, and the proudly standing pine looks as if it's telling the viewers how strong and solemn it is. Some of the pavilions were painted with exquisite brushwork, which is enriched by the contrast with the layered mountains. His use of ink was also skillful, in this painting, the ink looked light yet didn't lack the feeling of thickness; it was used freely and vividly. Even when we appreciate the painting today, we can still taste the richness inside.

Wang Gai in Qing Dynasty described Guo Xi in the following way: "In early years, he painted elegantly; as he got old, his use of brush became stronger and stronger, the mountain tops in his paintings often had the shape of clouds, which created a magnificent feeling". In other words, when painting mountains, Guo $\mathrm{Xi}$ would use methods similar to how clouds were painted, reflecting the metaphor of "peculiar peaks are often seen in summer clouds", which is why this method was referred to by later generations as "cloud stroke" (also known as rolling-cloud stroke). In fact, this method of painting mountains was a realistic expression of igneous rock mountains that often look round and towering. This characteristic method can be seen in Early Spring and Painting of Nest and Stones. In these paintings, his use of the brush looks powerful, without much use of sharp brush; instead, the medium part of the brush was more used, thus obtaining the magnificent manner in each wielding of the brush; at the same time, few strokes were used on the internal side of the stones, thus vividly showing the special shape of mountains with igneous rocks. When commenting on Li Cheng's painting method, Zhang Geng said that "he didn't use many strokes yet created rich layers, side strokes were not much used yet the landscapes naturally looked strong", which was also the characteristics of strokes of Guo Xi. In the Painting of Serene Valley, he expressed the freezing atmosphere of the snow at the mountaintop. His vivid expression was on the basis of the observation of laminated rocks. The rocks were painted through layered strokes, showing that his use of techniques followed the changes of the real structure of rocks.

In his landscape paintings, Guo $\mathrm{Xi}$ absorbed the typical characteristic of "capturing the flowing of mists and the layers of mountains" in Li Cheng's paintings. Generally speaking, Guo Xi absorbed the northern composition of lofty mountains and floating clouds and waters in his expression of widely stretching mountains. When we appreciate carefully, Guo Xi's works seem to have reached the acme of perfection, yet they were never soft. On the contrary, Guo Xi was capable of expressing powerful mountains and stones with sharp and thin brushwork. Therefore, through the analysis of Guo Xi's landscape paintings, it can be seen that he had absorbed both the southern and the northern styles in their spirits and artistic conceptions. 


\section{THE INFLUENCE OF GUO XI'S LANDSCAPE PAINTINGS}

During the reign of Emperor Shenzong, Guo Xi's painting style gradually became the mainstream in the painting academy. On the one hand, it's because of the preference and support of the emperor; on the other hand, it's because Guo Xi's painting skills were indeed outstanding. Later on, the emperor even entrusted him to "evaluate painters all over the country", which further promoted the social influence and status of Guo Xi's style. For that reason, most painters in that age learned his styles. In the Northern Song Dynasty, the creation of landscape paintings was greatly influenced by $\mathrm{Guo} \mathrm{Xi}$, and the rapid progress and comprehensive development of landscape paintings could not have been achieved without the achievements made by Guo Xi. In the history of Chinese landscape painting, Guo $\mathrm{Xi}$, Li Cheng and Fan Kuan represented the highest achievements made in the Northern Song Dynasty. Among the early successors of Li Cheng, Xu Daoning was the most outstanding, who kept the essential part of Li Cheng's painting. However, throughout the history of landscape painting, the achievements made by $\mathrm{Xu}$ Daoning could not be compared with those made by $\mathrm{Li}$ Cheng. The appearance of Guo Xi, had finally led to a brilliant development of landscape painting in the Northern Song Dynasty.

Guo $\mathrm{Xi}$ observed the changes of the nature in different seasons in a highly detailed way. When observing the nature, Guo Xi held that observe from different directions, angles, distances and times, thus observing the changes in spring, summer, autumn and winter, that the painters should put themselves in time and space to feel the splendid views, thus enabling people to fully express the nature and get close to the nature. Guo Xi "learned the theories of the Taoism when he was young" and "travelled to remote places". He liked travelling, which was one of the fundamental requirements of painters. Guo Xi viewed the nature from the essence of "human feelings", "limitations of earthly things are always against human feelings", while "unearthly mists are what human feelings have always longed for yet could not see". Human feelings refer to human nature, and in the nature, all humans hate earthly lives and long for tranquil and pleasant places. Therefore, the behavior of "virtuous people" to escape the official career and lively quietly in remote places was a behavior of abandoning the earthly shackles, "the ambition of forests and springs, and the companionship of the mists are what we have seen in dreams". In Linquan Gaozhi, he described the images of natural landscapes in the following way: "mountains looks delightful like smiles in spring, verdant like a drop in summer, clear as if with make-ups in autumn, and gloomy as if sleeping in winter". Such a wonderful summary makes us deeply feel how much Guo Xi loved the nature. He required painters to involve themselves in the nature, thus expressing their feelings through nature. Guo Xi showed us in a vivid way that "art comes from life yet goes beyond life". Each of Guo Xi's paintings has been an expression of such experience, which would naturally be transformed into a "fusion of feelings and natural settings". These theories that he developed in the process of painting are still of great significance of guidance in the $21^{\text {st }}$ century.

\section{CONCLUSION}

In a word, Guo Xi expressed the "fusion of feelings and natural settings" through his powerful brushwork, and such techniques as withered trees, crab-claw branches, rolling-cloud strokes and towering cliffs have influenced generation after generation of landscape painters. In addition, he had made a great contribution to the expression of early spring landscapes and cold forests, two typical themes in Chinese landscape painting.

\section{References}

[1] Wang Bomin. Comprehensive History of Chinese Painting [M] Beijing: SDX Joint Publishing Company. 2018(11).

[2] Peng Lai. Ancient Painting Theories [M]. Shanghai Bookstore Publishing House. 2009(1).

[3] Jia Tao. Outline of Chinese Painting Theories. Culture and Art Publishing House. 2005(4)

[4] Wang Huangsheng, Hu Guanghua. Special History of Chinese Painting : Landscape Painting [M]. Jiangxi Fine Arts Publishing House. 2008(12).

[5] Xu Gufuan. The Spirits of Chinese Art [M]. Guangxi Normal University Press. Edition 1. 2007(1), printed for the second time in 2008(2)

[6] Guo Xi (Song Dynasty). Proofread and annotated by Zhou Yuanbin. Linquan Gaozhi [M]. Shandong Pictorial Publishing House. 2010(8).

[7] Ji Yun et al. (Qing Dynasty). Complete Library in the Four Branches of Literature [M]. Shanghai: Shanghai Classics Publishing House, 1987.

[8] $\mathrm{Xu}$ Shucheng. History of Painting in the Song Dynasty [M] Beijing: People's Fine Arts Publishing House. 2000:49-54

[9] Wang Kewen. Words about Landscape Painting [M]. Shanghai People's Fine Arts Publishing House. Edition 1. 1st printing. 1993(8).

[10] Wu Fei. Comprehensive Works in Chinese Landscape Painting: Linquan Gaozhi $[\mathrm{M}]$. Shanghai Calligraphy \& Painting Publishing House. 2006, Edition 1.

[11] Yang Danian. Selection of Painting Theories in All Dynasties in China [M]. Jiangsu Education Publishing House. Edition 1. 2005(1). 